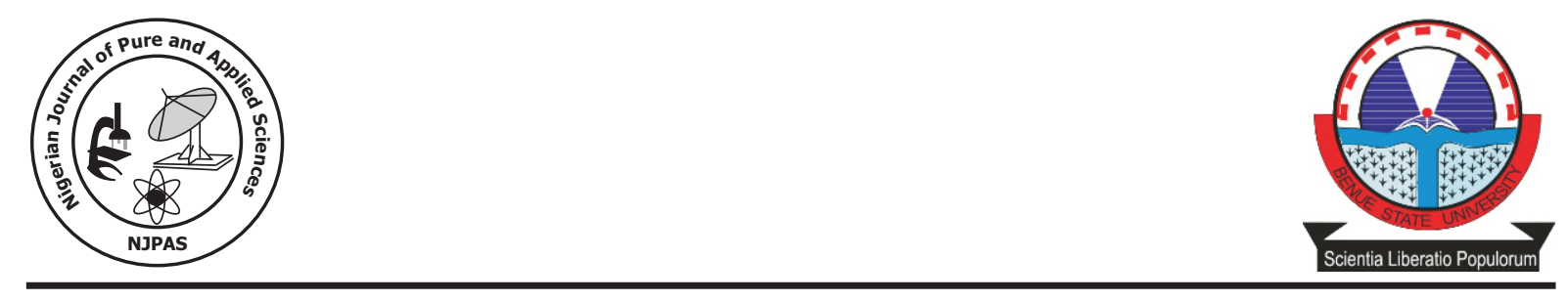

\title{
Salmonella Enteric Fevers and Microbial Contamination in Public Eating Places in Makurdi, Nigeria.
}

\author{
${ }^{1}$ Utume, L. N., ${ }^{2}$ Amuta, E. U., ${ }^{3}$ Mbaawuaga, E. M. and ${ }^{3}$ Omudu, E. A. \\ ${ }^{1}$ Department of Medical Microbiology and Parasitology, \\ Benue State University College of Health Sciences, Makurdi. \\ ${ }^{2}$ Department of Biological Sciences, University of Agriculture Makurdi \\ ${ }^{3}$ Department of Biological Sciences, Benue State University, Makurdi
}

\begin{abstract}
Food, drinking water, table and utensil swab and hand washing water samples were examined for Salmonella sp contamination. Microbiological examination of samples using lactose broth, CystineLactose-Electrolyte-Deficient (CLED) agar and Eosin-Methylene-Blue (EMB) agar was done to identify Salmonella $s p$, other organisms and indicator organisms. Indicator organisms identified were Aerobocter aerogenes and Escherichia coli. Other organisms include Streptococcus faecalis, Proteus sp and Staphylococcus aureus. $74.7 \%$ of examined samples showed Salmonella sp contamination while $89.8 \%$ of examined samples were contaminated with indicator organisms. Observed Salmonella sp were also examined biochemically to identify different species/strains. Species/strains identified were Salmonella typhi, S. paratyphi A, S. paratyphi B, S. cholerae-suis, S. enteritidis. There was a significant association between sanitary conditions and the occurrence of $S$. typhi in food, water, surroundings. It is very likely that poor hygiene and sanitary conditions encourage the occurrence of $S$. typhi in water, food, surroundings. Personal and environmental hygiene should be strictly adhered to especially in the study area so as to prevent and control S. typhi infections.
\end{abstract}

\section{Introduction}

Cases of human infections with Salmonella $s p$ have been reported throughout the world especially in developing countries; Nigeria inclusive. About 17 million cases occur annually in the world with not less than 600,000 deaths, (Jombo et al., 2006; CMAJ, 2003; Attah, 2000; Adams and Moss, 1999; Edleman and Levine, 1986). Although minor seasonal variations in the incidence of Salmonella infections have been reported, it is generally believed that microbial infections occur sporadically throughout the year in tropical climates and in developing countries because of the low socioeconomic and hygiene status. Places like Asia, Africa and Latin America are highly endemic areas (Jombo et al., 2006; Attah, 2000). Statistics show that in the west, the occurrence of enteric fevers caused by Salmonella $s p$ is as low as 0.2 per 100,000 persons in a year. In as much as accurate statistics is lacking, the occurrence in developing countries has been documented to be higher -13 to 22 per 100 , 000 persons per year. Enteric fevers constitute a serious socio-medical problem in 
developing economies (Jombo et al., 2006; Umeh and Agbulu, 2009)

The main route of infection being faecooral (Prüss-Üstün et al., 2010; Umeh and Agbulu, 2009; Rane, 2011; Nkere et al., 2011), these organisms reach food directly or indirectly from animal excreta at the time of slaughter, from human excreta, drinking water contaminated with sewage; also in the kitchen, the organisms may be transferred from raw to cooked food by hands, surfaces, utensils and other equipments. Objects like door handles, car steer-rings, water closet handles, paper and bank notes are also contaminants. Generally poor environmental sanitary conditions and poor personal hygiene are largely responsible for much of the contamination and cross-contamination (Nkere et al., 2011; Agustina et al., 2013; Adeleke et al., 2012; Adams and Moss, 1999 Akinyemi, Smith, Oyefolu, Bola and Coker, 2004; CMAJ, 2003; Attah, 2000; Prüss-Üstün et al., 2010; Ibe and Wariso, 1996). These infections are more likely to occur if the organisms are ingested in considerable amounts of at least $10^{6}$ organisms per inoculum). It is noteworthy that a chance contamination of food, water or other items with small number of microorganisms may not be harmful unless they are allowed to multiply; for instance if in food and the food is allowed to stand for hours in a warm room or environment. In resource-poor and tropical countries, cooked food meant for vending is often preserved at ambient temperatures long before consumption thus providing a viable substrate for the bacteria to multiply and attain an infective dose (Nkere et al., 2011; Adams and Moss, 1999; Rane, 2011).

The onset of illness is usually after an incubation period of about $7-14$ days and above of consumption of contaminated food or water and symptoms though unspecific is characterized by fever with low pulse rate associated with some strains of the organism, headache, mental confusion, abdominal tenderness and pain and diarrhea as well as occasional vomiting. The illness resulting from infections lasts 1-8 days or longer, depending on the virulence of the strain/type of microorganism; enteric fevers caused by $S$. paratyphi are milder compared to S. typhi. One of the most common consequences of enteric fevers is ileal perforation (Umeh and Agbulu, 2009; Attah, 2000; Mweu and English, 2008).

Similar reports and research studies are quite few in our immediate environment (Adams and Moss, 1999; Attah, 2000; Edino, Mohammed and Uba, 2004; Umeh and Agbulu, 2009; Jombo et al., 2006) in as much as enteric fevers are still a major disease of public health importance in Nigeria and the rest of Africa. With the concentration of earlier studies carried out being more on the clinical manifestations, epidemiological presentation and chemotherapy of these microbial infections, the focus of this study is on the public health aspects.

This study was set up to examine the impact of contamination of food, water and utensils with sanitary conditions of the surroundings of such places on the spread of enteric fevers in the study area and to highlight the roles of public eating places as sources of infection. It also hopes to provide scientific evidence-based information for the planning and implementation of preventive intervention programs that will highlight the need to improve sanitary/hygiene conditions at personal and public levels. Observations on these investigations are important markers in the spread of microbial infections especially enteric fevers in Makurdi metropolis, Benue State and Nigeria at large.

\section{Materials and methods}

\section{Description of Study Area}

Makurdi metropolis, the capital city of Benue State is located within the NigerBenue trough along the bank of the River Benue.

The town is located between latitude $7^{0}$ 30: $7^{0} 43^{\prime} \mathrm{N}$ and longitude $8^{0} 30: 8^{0} 35^{\prime} \mathrm{E}$. The mean monthly temperature is between $22^{\circ} \mathrm{C}$ $38^{\circ} \mathrm{C}$ and the mean annual rainfall range is 
between $150 \mathrm{~mm}-180 \mathrm{~mm}$. The town has a typical high tropical climate with two clearly marked seasons; rainy season which is prolonged and starts from the month of April to early October and the dry season that begins in late October and ends in March. During the prolonged rainy season, most areas become swampy due to the low water table of the town.

The soil types include clay, sandy and loamy soils of which sandy and loamy soils are predominant. Peasant fishing and farming are the main occupations of the local indigenes (Tiv and Jukuns ) of the area with a few into commercial farming of crops like yam, rice, guinea corn, Soya beans, maize, cassava and some vegetables like okra, tomatoes and pepper. It is a noteworthy fact that fishing is carried out throughout the year (during both seasons) because of the nature of the Benue River - it is not an ephemeral river.

The Benue State Environment Sanitation Authority (BENSESA) is a State Parastatal that is chiefly responsible for the environment and especially sanitation matters. It ensures that surroundings are kept clean by placing refuse bins in strategic locations in the metropolis and picking them up when full with waste, they also try to control indiscriminate refuse dumping by residents and ensure that all residents comply with selected sanitation days. Every last Saturday of the month is set aside as the sanitation day in Makurdi and it lasts from 6am to 9am. In as much as BENSESA tries to ensure a clean environment for the town and its residents, not much has been achieved in this regard as the sanitary situation of the town is still a thing of worry.

Food vending is a very common business endeavor in the metropolis. Food vending outlets range from table top vendors, mobile trucks, wooden sheds and huts to fast food joints, eateries and restaurants. These eating outlets are seriously patronized on every other day and hour and especially during lunch hours on work days. Every food vendor, operates his/her food vending outlet in his/her own unique way as there is no regulating body that checks the activities (cooking methods, hygiene/sanitary standards of the food handlers and general surroundings) of these food vendors. The residents therefore choose their eating outlets of their own volitions.

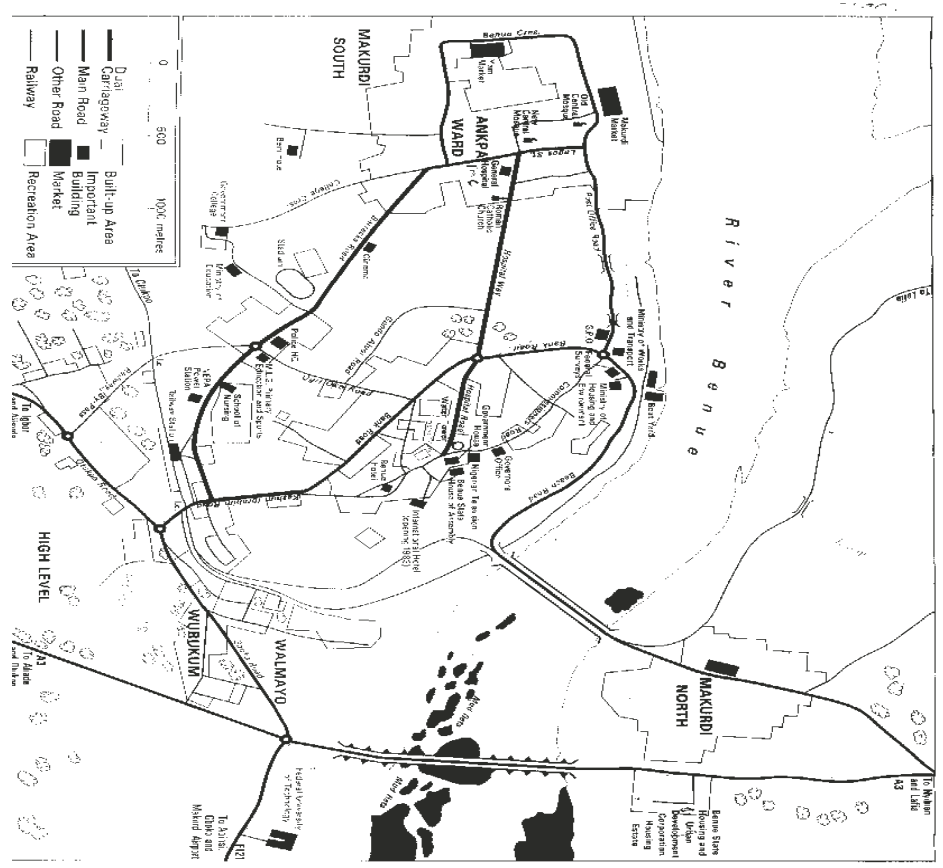

Fig. 1 Map of the study area showing sample collection locations. 


\section{Sample Collection and Media Preparation}

The sampling was done randomly in the major areas of the town which include North Bank (Makurdi North), Walmayo (Low level), Wurukum, High level, Ankpa ward and Wadata (Makurdi South). The public eating outlets were selected from every other street (three or four streets apart) in a particular area.

The sampling units were broadly divided into two, the unrestricted and restricted eating outlets. The two groups were further sub-grouped as below:

Unrestricted eating outlets:

-Wooden sheds.

-Huts.

- Table top sellers.

Restricted eating outlets:

-Eateries

-Restaurants

From each sub-group, five different samples were collected (food, water utensil swab, surface swab and hand washing water samples) using sterile steel spoons, plastic bags, glass bottles and cotton swabs. A total of two hundred and twenty five (225) samples were collected from both restricted and unrestricted eating outlets.

Bacterial media and stains were prepared according to standard laboratory preparations and instructions provided by the companies on the media or stain labels. Media and stains used include

- $\quad$ Cystine- Lactose- Electrolyte Deficient (CLED) agar.

- Eosin Methylene Blue (EMB) agar.

- Lactose broth

- Mannitol salt agar.

- $\quad$ Kliger Iron agar (KIA)

- Gram stains (gential violet and safranin)

\section{Microbiological and Biochemical Examination of Samples}

Microbiologically, approximately $10 \mathrm{~g}$ of collected solid samples (food and utensil swabs) were washed in $100 \mathrm{ml}$ of sterile water and $1 \mathrm{ml}$ of the washing inoculated in the lactose broth using a sterile pipette and the CLED agar using a sterile wire loop. They were both incubated at $37^{\circ} \mathrm{C}$ for $24 \mathrm{hrs}$ (note that inoculation was done on the same day as collection to avoid spoilage of food samples). The contents of the test tubes (lactose broth) that indicated growth were then inoculated on EMB agar and also incubated for $24 \mathrm{hrs}$ at $37^{\circ} \mathrm{C}$. Using a sterile pipette, $1 \mathrm{ml}$ of all liquid samples (drinking and hand washing water) were also inoculated as described for solid samples above.

Suspected microbial colonies from the microbiological examinations were tested biochemically so as to confirm their unique identities. Colonies were Gram stained using the standard procedures (Cheesbrough, 2006). The colonies were also inoculated in Mannitol salt agar and KIA agar and using procedures (Cheesbrough, 2006), the reactions in both agars were then observed and recorded.

Records of Widal tests carried out at the Federal Medical Centre over a period of four and a half years (2000 - July 2005) were also examined to check the frequency of occurrence of disease in the metropolis as it is a referral hospital as such records obtained would fairly represent the area. This was done so as to complement and substantiate the results gotten from the field.

\section{Results}

The results showed that out of the 225 samples collected, about $168(74.7 \%)$ of examined samples showed contamination with Salmonella sp (Table 1). Two hundred and twenty two $(98.6 \%)$ of the samples showed faecal contamination with evidence of Escherichia coli (33.8\%), Aerobacter aerogenes (20.0\%) and Streptococcus faecalis $(36.0 \%)$ as indicator organisms (Table 2). The presence of these indicator organisms shows the presence and threat of other enteric fever causing pathogens other than Salmonella sp. 
Table 1: Distribution of Salmonella sp.in Eating Outlets

\begin{tabular}{lllllll}
\hline Samples & $\begin{array}{l}\text { S. typhii } \\
(\%)\end{array}$ & $\begin{array}{l}\text { S. paratyphii } \\
\text { A }(\%)\end{array}$ & $\begin{array}{l}\text { S. paratyphii } \\
\text { B }(\%)\end{array}$ & $\begin{array}{l}\text { S. } \\
\text { cholerae- } \\
\text { suis }(\%)\end{array}$ & $\begin{array}{l}\text { S. } \\
\text { enteritidis } \\
(\%)\end{array}$ & $\begin{array}{l}\text { TOTAL } \\
(\%)\end{array}$ \\
\hline Food(jollof rice) & $13(5.8)$ & $7(3.1)$ & $5(2.2)$ & $3(1.3)$ & $9(4.0)$ & $37(16.4)$ \\
Drinking water & $9(4.0)$ & $4(1.8)$ & $2(0.9)$ & $9(4.0)$ & $11(4.9)$ & $35(15.6)$ \\
Table top swab & $8(3.6)$ & $5(2.2)$ & $0(0.0)$ & $4(1.8)$ & $0(0.0)$ & $17(7.6)$ \\
Utensil swab & $3(1.3)$ & $2(0.9)$ & $1(0.4)$ & $5(2.2)$ & $7(3.1)$ & $18(8.0)$ \\
Hand washing & $19(8.4)$ & $3(1.3)$ & $9(4.0)$ & $13(5.8)$ & $17(7.6)$ & $61(27.1)$ \\
water & & & & & & \\
\hline TOTAL (\%) & $52(23.1)$ & $21(9.3)$ & $17(7.6)$ & $34(15.1)$ & $44(19.6)$ & $168(74.7)$ \\
\hline
\end{tabular}

Table 2: Mean Distribution of Salmonella spin all Examined Samples

\begin{tabular}{lll}
\hline Samples & Salmonella sp Sum (\%) & Salmonella sp Mean (\%) \\
\hline Food (jollof rice) & $37(22.0)$ & $7.4(20.0)$ \\
Drinking water & $35(20.8)$ & $7.0(20.0)$ \\
Table top swab & $17(10.1)$ & $3.4(20.0)$ \\
Utensil swab & $18(10.7)$ & $3.6(20.0)$ \\
Hand washing water & $61(36.3)$ & $12.2(20.0)$ \\
\hline Total & 168 & $33.6(20.0)$ \\
\hline
\end{tabular}

$(\mathrm{x})=33.6(20.0)$

Microbial examination also showed organisms like Non lactose fermenting E. coli (1.8\%), Coagulase negative Staphylococcus (0.4\%), Klebsiella sp (1.3\%), Staphylococcus aureus (1.3\%), Proteus sp (1.8\%) and Diptheroids $(2.2 \%)$ though in negligible amounts.

Using SPSS version 10.0 (2003), Chisquare tests showed that sanitary conditions are significant in Salmonella sp contamination of an eating outlet $(\mathrm{p}<0.05)$. It also showed that the contamination and multiplication of a microorganism in a medium (be it food, water or surfaces) is also significantly affected by sanitary conditions $(\mathrm{p}<0.05)$. Simple descriptive analysis reveals that a total of one hundred and sixty eight Salmonella $s p$ colonies were isolated from all the samples examined, with a mean frequency of 33.6 $(20.0 \%)$, it shows that contamination is high.

Table 3: Distribution of organisms other than Salmonella spin Eating Outlets

\begin{tabular}{|c|c|c|c|c|c|c|c|c|c|c|}
\hline Samples & $\begin{array}{c}\text { Strep. } \\
\text { Faecalis } \\
(\%)\end{array}$ & $\begin{array}{c}E . \text { coli } \\
(\%)\end{array}$ & $\begin{array}{c}A . \\
\text { aerogen } \\
\text { es }(\%)\end{array}$ & $\begin{array}{c}\text { Non. } \\
\text { Lac. } \\
\text { Fer } \\
\text { E.coli } \\
(\%)\end{array}$ & $\begin{array}{l}\text { Coa. - } \\
\text { Ve } \\
\text { staph } \\
(\%)\end{array}$ & $\begin{array}{l}\text { Kleb } \\
\text { spp } \\
(\%)\end{array}$ & $\begin{array}{c}\text { Staph } \\
\text { aureus } \\
(\%)\end{array}$ & $\begin{array}{c}\text { Proteus } \\
\text { spp } \\
(\%)\end{array}$ & $\begin{array}{c}\text { Diphth } \\
\text {-eriods } \\
\quad(\%)\end{array}$ & $\begin{array}{c}\text { Total } \\
(\%)\end{array}$ \\
\hline $\begin{array}{l}\text { Food } \\
\text { (jollof rice) }\end{array}$ & $17(7.6)$ & $21(9.3)$ & $14(6.2)$ & $1(0.4)$ & $0(0)$ & $0(0)$ & $2(0.9)$ & $1(0.4)$ & $0(0)$ & $56(24.9)$ \\
\hline Drinking water & $18(8.0)$ & $14(6.2)$ & $11(4.9)$ & $0(0)$ & $1(0.4)$ & $1(0.4)$ & $1(0.4)$ & $0(0)$ & $1(0.4)$ & 47(20.9) \\
\hline Table top swabs & $8(3.6)$ & $0(0)$ & $6(2.7)$ & $0(0)$ & $0(0)$ & $2(0.9)$ & $0(0)$ & $1(0.4)$ & $2(0.9)$ & $19(8.4)$ \\
\hline Utensil swabs & $15(6.7)$ & $9(4.0)$ & $1(0.4)$ & $1(0.4)$ & $0(0)$ & $0(0)$ & $0(0)$ & $0(0)$ & $1(0.4)$ & $27(12.0)$ \\
\hline $\begin{array}{l}\text { Hand washing } \\
\text { water }\end{array}$ & $23(10.2)$ & $32(14.2)$ & $13(5.8)$ & $2(0.9)$ & $0(0)$ & $0(0)$ & $0(0)$ & $2(0.9)$ & $1(0.4)$ & $73(32.4)$ \\
\hline Total & $81(36.0)$ & $76(33.8)$ & $45(20.0)$ & $4(1.8)$ & $1(0.4)$ & $3(1.3)$ & $3(1.3)$ & $4(1.8)$ & $5(2.2)$ & 222(98.6) \\
\hline
\end{tabular}

Widal test results from Federal Medical Centre (FMC) Makurdi over the past four and a half $\left(4 \frac{1}{2}\right)$ years showed that the rate of occurrence was high and fluctuated over the years. This confirms the high rate of occurrence of Salmonella enteric fevers in the metropolis.

\section{Discussion}

The findings of this study show that Salmonella enteric fevers especially typhoid fever are a serious health problem in Makurdi. This study aligns with previous studies which argue that universal occurrence and high endemicity in most parts of the country and 
most developing nations is attributed to poor personal hygiene and environmental sanitary conditions of not just the cooking area but the entire environs (Akinyemi et al., 2004; Ibe and Wariso, 1996; Agustina et al., 2013; Rane, 2011; Umeh and Agbulu, 2009; Nkere et al., 2011; Mweu and English, 2008; Kariuki, 2008; Prüss-Üstün et al., 2010). This is evident from the high prevalence of Salmonella $s p$ as observed from examined samples 168(74.7\%) and the records of FMC, Makurdi. FMC records show that there has been a gradual increase in the rate of infection with Salmonella sp. The worst case scenario posing to be 2005 where for only seven (7) months, $256(68.63 \%)$ of patients screened for typhoid fever were tested positive.

The results of this study also showed that the type of public eating outlet (whether huts or restaurants) did not significantly affect the rate of contamination with microorganisms; in as much as the restaurants and eateries presented a more neat environment, the contamination rate was basically the same as that of huts and other open vending points. It was also observed that the samples collected at the beginning of the study were more laden with microorganisms than the samples collected towards the end of the work. This was suspected to be so because the food vendors and handlers were more or less taken unawares at the start of the study and were seen to adjust their hygiene and sanitation practices as the study progressed and ended. This should not be the case as hygiene and good sanitary conditions should be paramount for every food vendor. The general lack of knowledge in basic hygiene practices and food safety measures portrayed by food vendors in the area is seen to be the major contributing factor to this current low level of personal and environmental hygiene.

This study agrees with similar studies (Umeh and Agbulu, 2009; Attah, 2000; Akinyemi et al., 2004; Nkere et al., 2011; Rane, 2011; Kariuki, 2008) that sanitary conditions are significant in the multiplication of microorganisms in food, water and surroundings. The initial contamination of food, water, equipments and surroundings is possible through poor sanitary and hygiene practices especially toiletry habits. The contamination chain often starts at the cleanup stage after defecation especially where the hand comes in contact with faeces and is not properly washed with clean water and soap or ash, the line of contamination via contact continues with items like the water closet handle, door knobs, tables, water, food, spoons and key rings amongst others till ingestion occurs one way or the other (Adeleke et al., 2012; Umeh and Agbulu, 2009; Akinyemi et al., 2004; CMAJ, 2003; Attah, 2000; Agustina et al., 2013; Adams and Moss, 1999; Ibe and Wariso, 1996). Food vendors and handlers in the metropolis were seen to exhibit poor hand hygiene (hand washing) practices as it was evident from the results of the hand washing samples collected and examined (Table 2).

Salmonella ( $S$. typhi) infections cut across all age groups, (Prüss-Üstün et al., 2010; Umeh and Agbulu, 2009; Emew and English, 2008; Galan, 2003; Postgate, 1985; Wistreich and Lechtman, 1973), however as observed from FMC Makurdi records, infection seems to be highest within the age bracket of $18-35$ years. This is believed to be so because this age bracket is the labour/productive age group and because these groups of persons spend more time in their work places than their homes, they tend to eat more vended foods than meals prepared in their homes so as to ensure they are at their work places/businesses. This therefore exposes them to infections via food and drink (water).

\section{Conclusion}

In conclusion, it is noteworthy that this seemingly high rate of microbial contamination can be controlled if personal hygiene and sanitary conditions in the metropolis are properly regulated. In view of the above findings, the authors wish to make the following recommendations. 
-Personal hygiene, waste and sewage management and water purification campaigns should be mounted by Government in collaboration with NonGovernmental organizations to create awareness and effectively sensitize the populace.

- Better and more efficient methods of detection and treatment should be evolved since the major source of contamination is infected humans.

- $\quad$ Routine checks should also be carried out by Public Health workers in public eating outlets periodically (for instance every quarterly in a year), to check their hygiene standards and contaminations of any sorts.

- Infected persons detected from such routine checks should be excluded from handling food especially in public eating outlets, until such a person's faeces when examined, fails to grow Salmonellae for 3 consecutive specimens.

- Laws should also be enforced to ensure that adequate and high standards of Public Health are maintained in all public eating outlets.

- Government needs to dedicate a department or Parastatal that will effectively and efficiently control public health issues. Such should also be saddled with the responsibility of regulating the operations of public food vending.

\section{Reference}

Adams, M. R. and Moss, M. O. (1999) Food Microbiology, Royal Society of Chemistry, Cambridge. pp398.

Adeleke, M. A., Hassan, A. O.,Ayepola, T. T., Famodimu, T. M., Adebimpe, W. O., and Olatunde, G. O. (2012) Public Health Risks Associated with Apples and Carrots Sold in Major Markets in Oshogbo, Southwest Nigeria. Journal of Toxicology and Environmental Health Sciences 4(8):140-144.
Agustina, R., Sari, T. P., Satroamidjojo, S., Bovee- Oudenhoven, M. J. I., Feskens, J.and Kok, F. J. (2013) Association of Food Hygiene Practices and Diarrhea Prevalence among Indonesian Young Children in Low Socio-economic Urban Areas. BioMed Central Public Health 13(977):1471.

Akinyemi, K.O, Smith, S.I., Oyefolu, Bola, A.O. and Coker, A.O. (2004) Typhoid and Bacteria Co-infection, College of Medicine, University of Lagos. pp 16.

Attah, B. Ed (2000) Human Pathology: A Complete Text for Africa, Ibadan University Press, Ibadan.

Canadian Medical Association Journal, CMAJ (2003) Typhoid Fever pp132.

Cheesbrough, M. (2006) District Laboratory Practice in Medical Tropical Countries, Second Edition Update. Vol. II, Cambridge University Press, Cambridge.

Edelman, R. and Levine, M.M. (1986) Summary of an International Workshop on Typhoid Fever Rev. Infectious Diseases 8(3):899-901.

Edino, S.T., Mohammed, A.Z. and Uba, A.F, (2004) Typhoid Enteric Perforation in North Western Nigeria. Nigerian Journal of Medicine 15(4):345.

Ibe, S.N. and Wariso, B.A. (1996) Drug Susceptibility Profile of Salmonellae typhi Blood Isolates in Port Harcourt, Nigeria. West African Journal of Medicine, 15(4):219.

Jombo, G., Enenebeaku, M. and Utsalo, S. (2006) Clinical Diagnosis of Enteric Fever and The Potential Benefits in the Management of Enteric Fevers in the Developing World. The Internet Journal of Parasitic Diseases 2(2). 
Kariuki, S. (2008) Typhoid Fever in SubSaharan Africa: Challenges of Diagnosis and Management of Infections. Journal of Infectious Diseases in Developing Countries 2(6):443-447.

Mweu, E. and English, M. (2008) Typhoid Fever in Children in Africa. Tropical Medicine and International Health 13(4):532-540.

Nkere, C. K., Ibe, N. I. and Iroegbu, C. U. (2011) Bacteriological Quality of Foods and Water Sold by Vendors and in Restaurants in Nsukka, Enugu State, Nigeria: A Comparative Study of Three Microbiological Methods. Journal of Health, Population and Nutrition 29(6):560-566.

Postgate, J. (1985) Microbes and Man New Ed, Pelican Books, Philadelphia.pp689.
Prüss-Üstün, A., Kay, D., Fewtrell, L. and Bartram, J. (2010) Unsafe Water, Sanitation and Hygiene. Comparative Quantification of Health Risks : A Bulletin of The World Health Organization(WHO) Chapter 16

Rane, S. (2011) Street Vended Food in Developing World: Hazard Analyses. Indian Journal of Microbiology 51(1):100-106.

Umeh, E. and Agbulu, C. (2009) Distribution Pattern of Salmonella Typhoidal Serotypes in Benue State, Central Nigeria. The Internet Journal of Epidemiology 8(1).

Wistreich, G.A. and Lechtman, M.D. (1973) Microbiology and Human Diseases. Glencoe Press, New York. 